\title{
Design and Implementation of Tester for Thermoelectric Parameter of Lithium Ion Battery and Its Electrode Materials
}

\author{
Yifeng Liu ${ }^{1}$, Liubin Song, ${ }^{2,}$, Jie Shen ${ }^{1}$, Jiao Liu $^{2}$, Zhongliang Xiao ${ }^{2}$ \\ ${ }^{1}$ Department of Art Design, Hunan Women's University, Hunan Changsha 410004, PR China. \\ ${ }^{2}$ School of Chemistry and Biological Engineering, Changsha University of Science and Technology, \\ Hunan Changsha 410004, PR China. \\ *E-mail: liubinsong1981@126.com
}

doi: $10.20964 / 2017.03 .31$

Received: 12 December 2016 / Accepted: 9 January 2017 / Published: 12 February 2017

\begin{abstract}
Thermal issues of lithium ion battery are key factors affecting the safety, operational performance, life and cost of lithium ion battery. Effective assessment on thermoelectric performance of lithium ion battery and its electrode materials is an important measure to improve the safety of lithium ion battery. In this paper, the tester for thermoelectric parameter of lithium ion battery was developed based on our previous thermo-electrochemical studies of $\mathrm{LiFePO}_{4}$ and $\mathrm{LiMn}_{2} \mathrm{O}_{4}$ materials for lithium ion battery [12]. The methods of electrochemical calorimetry, the visual identification system design, and the technological structure optimization and upgrading were applied to the appearance design, modular design, technological structure optimization, and application promotion for laboratory-used battery thermoelectric performance tester. The tester was used to study thermal and electric performance on $\mathrm{LiNi}_{0.5} \mathrm{Co}_{0.2} \mathrm{Mn}_{0.3} \mathrm{O}_{2}$ cathode materials at different ambient temperatures and charge-discharge rates. The results showed that the tester was of high intelligence and easy to operate. It was designed for measuring the capacity, the density of energy and the cycle life of lithium ion battery. The discharge specific capacity decreased with the increasing of charge-discharge rates and ambient temperatures. At low rate $(0.2 \mathrm{C})$ heat flow of battery increased slowly and appeared a plurality of exothermic peaks, but at high rates $(0.5 \mathrm{C}, 1.0 \mathrm{C}, 2.0 \mathrm{C})$ heat flow increased rapidly and only an exothermic peak appeared at the charge and discharge stage respectively. Through the study of thermoelectrochemistry, a series of thermodynamic parameters of lithium ion batteries during chargedischarge process were achieved. These works will contribute to the battery structure optimization and thermal management design.
\end{abstract}

Keywords: product design, lithium ion battery, thermoelectric performance, single electrode electrochemical calorimetry

FULL TEXT 
(C) 2017 The Authors. Published by ESG (www.electrochemsci.org). This article is an open access article distributed under the terms and conditions of the Creative Commons Attribution license (http://creativecommons.org/licenses/by/4.0/). 